\title{
Influência da atividade física na indução da autofagia e redução da incidência do câncer: revisão crítica dos mecanismos fisiológicos e metabólicos.
}

\author{
Influence of physical activity on autophagy inducing and reduction of cancer incidence: critical \\ review of physiological and metabolic mechanisms. \\ Influencia de la actividad física en la inducción de la autofagia y la reducción de la incidencia de \\ cáncer: una revision crítica de los mecanismos fisiológicos y metabólicos.
}

\begin{abstract}
Resumo
Objetivo: Descrever os principais mecanismos da autofagia estimulada por atividade física e sua relação com a redução na incidência de câncer. Material e métodos: Foram realizadas coletas de dados através da análise da literatura científica disponível nas bases de dados da MEDLINE, ScienceDirect e Wiley, de maneira independente e manual. Foram utilizados como descritores de busca os termos: "cancer", "autophagy" e "physical activity", e o período de tempo para as publicações compreendeu os anos de 1990 a 2020. O critério de inclusão foi: "trabalhos publicados dentro do escopo do estudo, publicados no intervalo de tempo citado". E como critério de exclusão: "trabalhos não relacionados ao tema de estudo e com relatos já ultrapassados de acordo com a literatura atual”. Resultados: A atividade física influência positivamente diversos sistemas, levando a alterações agudas e crônicas. Os benefícios em patologias metabólicas, imunes, cancerígenas, cardiovasculares, psiquiátricas e neurológicas são indiscutíveis e os mecanismos estão sendo elucidados. Autofagia medeia a digestão e reciclagem de partes obsoletas da célula durante a inanição e participa de uma variedade de processos fisiológicos de remoção residual. A autofagia é capaz de eliminar as microorganimos, agregados proteicos tóxicos, genotóxicos, desempenhando papéis durante a infecção, envelhecimento e patogênese de doenças. Conclusão: A partir da análise dos mecanismos envolvidos na autofagia induzida por atividade física ficaram postulados três pontos principais: 1) Via mTORC1 inativada por inanição, 2) Regulação por espécies reativas de oxigênio e hipóxia, 3) Regulação da autofagia por vias alternativas à mTORC1.
\end{abstract}

Palavras-chave: Autofagia; Exercício físico; Prevenção de doenças; Câncer.

\begin{abstract}
Objective: To describe the main mechanisms of autophagy stimulated by physical activity and its relationship with the reduction in the incidence of cancer. Material and methods: Data collections were carried out through the analysis of the scientific literature available in the MEDLINE, ScienceDirect and Wiley databases, independently and manually. The terms "cancer", "autophagy" and "physical activity" were used as search descriptors, and the period of time for publications covered the years 1990 to 2020. The inclusion criteria were: "works published within the scope of the study, published in the aforementioned period". And as an exclusion criterion: "works not related to the study topic and with reports that are already outdated according to current literature". Results: Physical activity positively influences different systems, leading to acute and chronic changes. The benefits in metabolic, immune, cancerous, cardiovascular, psychiatric and neurological pathologies are indisputable and the mechanisms are being elucidated. Autophagy mediates the digestion and recycling of obsolete cell parts during starvation and participates in a variety of physiological waste removal processes. Autophagy is able to eliminate microorganisms, toxic protein aggregates, genotoxic, playing roles during infection, aging and disease pathogenesis. Conclusion: From the analysis of the mechanisms involved in physical
\end{abstract}


activity-induced autophagy, three main points were postulated: 1) Via mTORC1 inactivated by starvation, 2) Regulation by reactive oxygen species and hypoxia, 3) Regulation of autophagy by alternative pathways to mTORC1.

Keywords: Autophagy; Exercise; Disease prevention; Cancer.

\begin{abstract}
Resumen
Objetivo: Conocer los principales mecanismos de autofagia descritos por la actividad física y su relación con la reducción de la incidencia de cáncer. Material y métodos: La recogida de datos se realizó mediante el análisis de la literatura científica disponible en las bases de datos MEDLINE, ScienceDirect y Wiley, de forma independiente y manual. Los términos "cáncer", "autofagia" y "actividad física" se utilizaron como descriptores de búsqueda, y el período de tiempo para las publicaciones abarcó los años 1990 a 2020. Los criterios de inclusión fueron: "trabajos publicados en el ámbito del estudio, publicados en el período mencionado". Y como criterio de exclusión: "trabajos no relacionados con el tema de estudio y con informes que ya están desactualizados según la literatura actual". Resultados: La actividad física influye positivamente en diferentes sistemas, provocando cambios agudos y crónicos. Los beneficios en patologías metabólicas, inmunitarias, cancerosas, cardiovasculares, psiquiátricas y neurológicas son indiscutibles y los mecanismos se están dilucidando. La autofagia media la digestión y reciclaje de partes celulares obsoletas durante inanición y participa en una variedad de procesos fisiológicos de eliminación de desechos. eliminar microorganismos, agregados proteicos tóxicos, genotóxicos, que juegan roles durante la infección, el envejecimiento y la patogénesis de la enfermedad. Conclusión: A partir del análisis de los mecanismos involucrados en la autofagia inducida por la actividad física, tres puntos principales Se postularon: 1) Vía mTORC1 inactivada por inanición, 2) Regulación por especies reactivas de oxígeno e hipoxia, 3) Regulación de la autofagia por vías alternativas a mTORC1.
\end{abstract}

Palabras clave: Autofagia; Ejercicio físico; Prevención de enfermedades; Neoplasias.

\title{
1. Introdução
}

A atividade física consolidou-se como fator protetor em diversas doenças, e o sedentarismo hoje é considerado um problema de saúde pública(Blair et al., 2004). Algumas doenças crônicas estão intrinsecamente ligadas à inaptidão física, como doenças cardiovasculares, diabetes, síndrome metabólica, hipertensão, osteoporose, depressão, doenças neurodegenerativas, obesidades e canceres(Sikorska-Siudek et al., 2006),(Matthews et al., 2001),(Cassilhas et al., 2016),(Andriolo et al., 2019),(Brambilla et al., 2011),(Marin Bosch et al., 2020). A fisiopatologia de algumas doenças e o mecanismo protetor relacionado já foram descritos, porém alguns mecanismos ainda continuam desconhecidos, como o mecanismo pelo qual a atividade física reduz a incidência de câncer(Chen et al., 2019),(Haydon et al., 2006).

O foco central deste trabalho é a redução da incidência de câncer relacionada à atividade física observada em estudos prévios e seus mecanismos. Objetivar-se-á em estabelecer uma linha lógica elencando os principais mecanismos correlatos da autofagia estimulada por exercício e redução na incidência de câncer.

\section{Material e Métodos}

O presente estudo analisou a literatura científica disponível nas bases de dados completas da MEDLINE, utilizando a ferramenta de busca PubMed (https://pubmed.ncbi.nlm.nih.gov/), ScienceDirect (https://www.sciencedirect.com/)e Wiley (https://onlinelibrary.wiley.com/), de maneira independente e manual. Foram utilizados como descritores de busca as palavras chaves: "cancer", "autophagy" e "physical activity". Estes termos foram combinados por intermédio do operador booleano AND. As buscas foram delimitadas para trabalhos publicados entre os anos de 1990 e 2020, em todos os idiomas. Como critério de inclusão foi considerado: "trabalhos publicados dentro do escopo do estudo dentro do intervalo de tempo citado e relacionados aos mecanismos moleculares" e como fator de exclusão foi considerado: "trabalhos não relacionados ao tema de estudo e com relatos já ultrapassados de acordo com a literatura atual”.

A coleta e análise dos dados foram realizadas de agosto de 2019 até novembro de 2020. Atualizando os dados de acordo com pesquisas recentes. Estudos considerados essências com datas de publicação posterior foram recrutados de forma manual e incluídos no escopo da revisão. 


\section{Resultados}

Nas bases de dados pesquisadas foram encontrados 3.398 artigos científicos, sendo 1.276 da MEDLINE 1.708 da ScienceDirect e 414 da Wiley.Destes, 342 foram elegíveis, foram encontradas 13 duplicadas, utilizando a ferramenta Mendeley, restando 329 que atendiam os critérios de seleção. Após leitura integral, foram selecionados 67 artigos, os quais que fazem parte deste trabalho. Os demais artigos foram incorporados ao trabalho por corresponderem à artigos essenciais.

\section{Atividade física}

O exercício físico é uma das poucas atividades que cursam com um estresse extremo ao organismo. Em termos comparativos o metabolismo corporal aumenta em cerca de $2.000 \%$ em uma maratona, e em contrapartida, um estado patológico com febre alta elevaria essa taxa em 100\%. Ademais, alterações fisiológicas antecedem ao início do exercício, ativando e credenciando de maneira sinérgica o cérebro, o sistema cardiovascular, pulmonar, metabólico e muscular a atenderem as demandas recrutadas (Guyton \& Hall, 2011),(Nobrega et al., 2014),(Hanakawa et al., 2003),(Richardson, 2003).

O simples fato de imaginar uma atividade física ativa pontos chaves no córtex cerebral, os quais apresentam convergência com a execução da atividade, levando a alterações em nosso corpo mesmo antes de iniciarmos a atividade (Aulianida et al., 2003),(Hanakawa et al., 2003). Estudos de neuroimagem identificaram áreas onde ocorrem a elaboração imaginativa do exercício físico, estas são: córtex parietal superior, sulco pré-central, córtex pré-frontal dorsolateral, área prémotora, motora suplementar, sulco pré-central superior, sulco intraparietal, giro supramarginal do córtex parietal, gânglios da base e parte posterolateral do cerebelo(Aulianida et al., 2003),(Hanakawa et al., 2003),(Hardwick et al., 2013). A execução do exercício físico aciona também outras áreas além destas citadas: área motora primária , giro pré-central , cerebelo anterior e Vérmis, putâmen, giro frontal, giro pós central (Hanakawa et al., 2003),(Hardwick et al., 2013),(Aulianida et al., 2003).

As ações cerebrais elaboradas, após uma complexa interação entre as diversas regiões, são encaminhadas através dos feixes descendentes de fibras neuronais até a placa motora culminando na execução do movimento. Ademais, existe um mecanismo de feedforward, que antecipa a movimentação por meio da ativação cerebral relacionada ao movimento, enviando sinais para o centro vasomotor na medula oblonga que confere uma diminuição do tônus parassimpático e aumento da atividade simpática, desviando o fluxo de nutrientes para músculos e cérebro (Nobrega et al., 2014),(Ichinose et al., 2014),(Guyton \& Hall, 2011).

A descarga noradrenérgica pelo centro vasomotor gera uma vasoconstrição no sistema esplâncnico, rins, pele, sistema venoso e uma mínima vasoconstrição no cérebro e músculos, desviando assim, o fluxo para estes órgãos. Esta descarga excita também a medula suprarrenal, responsável por liberar epinefrina na corrente sanguínea, causando uma ativação beta-adrenérgica. (Guyton \& Hall, 2011),(Michelini et al., 2015),(Richardson, 2003),(Nobrega et al., 2014),(Elizabeth, 1957).

A norepinefrina e epinefrina liberadas durante a atividade física têm efeitos cardiovasculares, neurológicos, musculares e metabólicos importantes para o exercício físico. A descarga adrenérgica autonômica age diminuindo o limiar de excitação do sistema musculoesquelético pela acetilcolina e aumentando sua liberação na fenda sináptica (Tsentsevitsky et al., 2019),(Michelini et al., 2015),(Rodrigues et al., 2019). Essa descarga também causa uma constrição nas arteríolas e artérias do sistema cutâneo, mucoso, visceral e nas veias através dos receptores alfa-adrenérgicos, e causam uma vasodilatação mediada por receptores adrenérgicos beta2 nas artérias e arteríolas cerebrais, musculares e coronárias, desviando o fluxo sanguíneo que pode aumentar em até 50 vezes no músculo.

Além disso, o débito cardíaco e a secreção das glândulas sudoríparas aumentam, no fígado a glicogenólise é ativada via receptores alfa1 e a gliconeogênese é ativada via receptores beta2. A secreção de insulina pancreática por meio do estímulo dos receptores alfa diminui, a lipólise que ocorre por meio de mecanismos de acoplamento termogênico aumenta, ocorre liberação 
de melatonina pela glândula pineal, aumento da excreção de hormônio antidiurético pela hipófise posterior, além de outras modificações sem maiores relevâncias neste exposto(L. Brunton et al., 2012).

No tangente ao metabolismo energético três sistemas são acionados com maior intensidade, sendo assim cruciais para a produção de ATP: o sistema da fosfocreatina-creatina, o sistema do glicogênio-ácido-lático e sistema aeróbico(Hargreaves \& Spriet, 2020),(Hawley et al., 2014),(Guyton \& Hall, 2011). O ATP faz-se necessário em pontos chaves para contração muscular: provimento do potencial excitatório $(\mathrm{Na}+\mathrm{K}+\mathrm{ATPase})$, recaptação de $\mathrm{Ca}^{2}+$ pelo reticulo sarcoplasmático $\left(\mathrm{Ca}^{2}+\mathrm{ATPase}\right)$, e produção de força através da ciclagem da ponte cruzada de actina-miosina (miosina ATPase)(Hawley et al., 2014),(Hargreaves \& Spriet, 2020).

A geração de ATP no início da atividade física fica a cargo dos sistemas da fosfocreatina-creatina e do glicogênioácido-lático e decaem com a continuação da atividade. Estas constatações foram realizadas através da medição da concentração de fosfocreatina, com decaimento, e aumento de ácido lático(Medbo \& Tabata, 1993), os substratos intramusculares são principalmente o glicogênio, fosfocreatina e triglicerídeos musculares(Hargreaves \& Spriet, 2020),(Romijn et al., 1993),(Van Loon et al., 2001). Para respaldar o maior uso da glicose e ácidos graxos livres extramusculares foram realizadas medidas das enzimas glicogênio fosforilase e a piruvato desidrogenase. A primeira tem um incremento rápido e curto, a segunda tem um incremento rápido e sustentado indicando recrutamento de substratos de fonte externa(Parolin et al., 1999). No fígado temos um aumento da gliconeogênese, ou ciclo de Cori, e da glicogenólise disponibilizando maior aporte energético durante o exercício, não obstante em altas intensidades ocorre uma baixa glicêmica (Ahlborg et al., 1974),(Coggan et al., 1995). Outros fatos que devem ser salientados são o aumento da permeabilidade à glicose no músculo, o desvio do fluxo sanguíneo e a resistência transitória à insulina no restante do organismo (Murphy et al., 2020),(David H. Wasserman, 2009),(McConell et al., 2020),(Sylow et al., 2017). A captação de glicose no músculo durante uma atividade física pode aumentar em até 50 vezes, as explicações prévias não são elucidativas, mas avanços na pesquisa explicitam um mecanismo complexo de acoplamento dos transportadores de glicose GLUT4, alterações metabólicas mediadas pela enzima AMPK e ativação da via da proteína G RAC1 (McConell et al., 2020),(Sylow et al., 2017). O desvio do fluxo sanguíneo durante a atividade física envolve três mecanismos principais:

1) Comando central, a atividade de regiões cerebrais incumbidas da ativação somatomora também se comunica com o centro cardiovascular no bulbo raquidiano, e são responsáveis pelo mecanismo de Feedforward, deferindo um aumento da atividade simpática e uma retirada parassimpática, colaborando com um aumento no débito cardíaco e na pressão arterial(Ichinose et al., 2014),(Nobrega et al., 2014),(Michelini et al., 2015);

2) Aferências arteriais periféricas, compostas pelos barorreceptores e quimiorreceptores. Os barorreceptores são terminações nervosas sensíveis aos estímulos mecânicos localizados nos seios carotídeos e no arco aórtico, sendo responsáveis por enviar informações sobre o aumento da pressão e regulam tanto a pressão quanto a frequência cardíaca, enviando sinais que diminuem a atividade simpática e aumentam a parassimpática. Os quimiorreceptores são amplamente distribuídos no sistema nervoso central (núcleo do trato solitário, núcleo retrotrapezóide, locus coeruleus, hipotálamo, núcleo da rafe, complexo préBötzinger), no seio carotídeo e no arco aórtico, e são responsivos ao aumento da pressão de $\mathrm{CO}_{2}$ e à acidificação resultante do aumento de íons de hidrogênio no liquido cerebrospinal, culminando em um aumento da frequência respiratória, maior oxigenação sanguínea e eliminação de carbono(Ichinose et al., 2014),(Michelini et al., 2015),(Nobrega et al., 2014),(Moreira et al., 2011),(Hawley et al., 2014). O fornecimento de oxigênio é o fator determinante deste mecanismos, a retirada vagal e a atividade simpática causam uma vasoconstrição periférica, desviando o fluxo sanguíneo de sistemas como o esplâncnico, o conector e responsável por distribuir eficientemente este volume de oxigênio é o coração (Richardson, 2003); 
3) Reflexo pressor do exercício. A atividade muscular é responsável pelo mecanismo de feedback que realiza manutenção do aporte sanguíneo na unidade motora recrutada. O metaborreflexo e o mecanorreflexo são os mecanismos operadores do reflexo pressor. Acredita-se que o mecanorreflexo é aferido pelas fibras aferentes musculares do tipo III, supõese a presença de sítios alostéricos que diminuem o limiar de despolarização destas fibras durante a atividade física. O metaborreflexo é a resposta gerada frente aos metabólitos produzidos durante a atividade muscular; esta resposta é mediada por metaborreceptores nos terminais aferentes das fibras do tipo IV e a hipótese é que os ligantes são um conjunto de moléculas e íons (bradicinina, potássio, ácido lático, produtos do ácido araquidônico, adenosina, ATP e fosfato diprotonado) (Nobrega et al., 2014),(Ichinose et al., 2014),(Michelini et al., 2015),(Hawley et al., 2014). Além disso, a tensão de cisalhamento laminar no endotélio vascular aumenta a tradução do mRNA responsável por sintetizar a enzina óxido nítrico sintase (eNOS) e, consequentemente, a liberação de óxido nítrico, um potente vasodilatador local (Harrison et al., 2006).

A resistência transitória à insulina é marcada pela liberação aguda de hormônios resistores que permitem maior aporte energético para o músculo recrutado. Estudos prévios demostraram que durante o exercício físico ocorre um aumento transitório de testosterona total livre, hormônio do crescimento (GH), hormônio adrenocorticotrófico (ACTH), cortisol e glucagon, os quais são resistores de insulina. Além disso, a liberação de glucagon ativa a glicogenólise e a gliconeogênese hepática, que associadas à mudança sistêmica desencadeada por hormônios e neurotransmissores, aumenta a glicose circulante e diminui o nível sérico de insulina (Kraemer et al., 1998),(David H. Wasserman, 2009),(D. H. Wasserman et al., 1989).

Recentemente, discute-se a viabilidade de o músculo, por meio do mecanismo de cross-talk, funcionar como um órgão endócrino e imunorregulador (Murphy et al., 2020),(Brambilla et al., 2011),(Koelwyn et al., 2020). As miocinas são descritas como mensageiros químicos de ação autócrina, parácrina e endócrina liberadas durante a contração muscular. A dualidade de algumas destas moléculas reforça os benefícios únicos do exercício físico.

A IL-6 é uma citocinina pró-inflamatória elevada em estados patológicos, porém, somente durante a contração muscular uma via bioquímica que fosforila a cinase c-Jun N-terminal é ativada para formação da apoliproteína-1, e o fator de transcrição NF-kB não é recrutado como acontece em estados inflamatórios. IL-6, IL-1, TNF-alfa, INF-y, MCP1 e outras moléculas próinflamatórias, encontram-se em níveis inferiores em atletas em comparação a indivíduos sedentários; em contraste, as células T $\mathrm{CD}^{+}$,responsáveis pelo monitoramento de células cancerígenas, encontra-se elevadas em atletas(Koelwyn et al., 2020),(Murphy et al., 2020).

O ácido beta-aminoisobutírico e o hormônio irisina, são estimuladores da expressão de PGC-1alfa (Proliferadores de peroxissoma gama), que acoplam a transformação de gordura branca em marrom, ativam a Beta-oxidação, regulam a gliconeogênese, e também são liberados durante a atividade física. Outras moléculas comunicantes com o cérebro(BNDF- Brainderived neurotrophic factor)e com o intestino (SPARC - Secreted protein acidic and rich in cysteine) realçam ainda mais a teoria do músculo como órgão endócrino (Murphy et al., 2020).

As hepatocinas são um grupo de mensageiros químicos liberados pelo fígado que regulam diversas funções extrahepáticas. Em relação à atividade física podemos elencar algumas hepatocinas liberadas e que regulam funções energéticas, metabólicas e celulares. A primeira delas é a HSP72, uma chaperona responsável por regular diversos mecanismos energéticos intracelulares e estruturais, assim como a retirada de proteínas danificadas (Murphy et al., 2020),(Mayer \& Bukau, 2005). A glicoproteína Folistatina e o fator de crescimento FGF21 (Fibroblast growth factor 21) estão elevados em pessoas com diabetes mellitus do tipo 2. Há um mecanismo envolvendo essas proteínas que age promovendo a resistência à insulina ao serem liberadas de forma aguda durante a atividade física, e após seu decréscimo sérico, a sensibilidade à insulina é regenerada(Hansen et al., 2016). 
À luz do exposto é possível inferir que a atividade física impacta de maneira sinérgica em diversos sistemas, levando a alterações agudas e crônicas. Ademais, os benefícios em patologias metabólicas, imunes, cancerígenas, cardiovasculares, psiquiátricas e neurológicas são indiscutíveis, e os mecanismos moleculares concernentes estão se elucidando com o avanço da ciência. Enfim, esses expostos fisiológicos, metabólicos e moleculares serão o cerne da discussão da ativação da autofagia relacionada à atividade física.

\section{Autofagia}

A autofagia é um processo evolutivamente conservador em que a célula eucariótica pode reciclar parte do seu próprio conteúdo por sequestrar uma parte do citoplasma em uma vesícula de membrana dupla que é entregue ao lisossomo para digestão. Ao contrário de outras maquinarias celulares de degradação, a autofagia remove proteínas de longa duração, macromoléculas, grandes complexos enzimáticos e organelas que se tornaram obsoletas ou danificadas. A autofagia medeia a digestão e reciclagem de partes não essenciais da célula durante a inanição e participa de uma variedade de processos fisiológicos, nos quais componentes celulares devem ser removidos para dar espaço para novos. Além disso, a autofagia é um processo celular capaz de eliminar microrganismos em células infectadas, agregados proteicos tóxicos, genotóxicos, e, portanto, desempenha um papel importante durante a infecção, no envelhecimento e na patogênese de muitas doenças(Levine et al., 2017).

A autofagia foi descrita pela primeira vez em meados de 1950 por Christian de Duve ao observar uma coleção de material amorfo no rim de recém nascidos em remodelação e estruturas vacuolares, com um conteúdo parcialmente digerido de materiais citoplasmáticos e mitocondriais, após perfusão de glucagon ou Triton WR-1339 no fígado (Jianhua Zhang, 2015). Essas estruturas fagocíticas foram denominadas autofagossomas, e na década de 1990 o pesquisador Yoshinori Oshumi lançou luz sobre a maquinaria responsável pela autofagia, cunhando o termo "genes relacionados à autofagia" (ATG) a partir de experimentos com leveduras do gênero Saccharomyces cerevisiae(Levine et al., 2017),(Jianhua Zhang, 2015).

A autofagia é classificada em três diferentes tipos denominados de microautofagia, autofagia mediada por chaperonas e macroautofagia (Sureshbabu et al., 2015). Cada uma destas vias está sob o controle de diferentes mecanismos como: inanição, baixa disponibilidade de glicose e ATP, baixos níveis séricos de insulina, estresse oxidativo, hipóxia entre outros mecanismos responsáveis pela inativação ou ativação da enzima cinase mTOR (Jianhua Zhang, 2015)'(Sureshbabu et al., 2015)'(Fritzen et al., 2016).

A microautofagia pode ser descrita como uma invaginação da membrana lisossomal com finalidade de captação e degradação de componentes do citosol, como lipídios, proteínas e organelas. No processo a membrana vacuolar se invagina formando uma estrutura tubular que engloba os componentes citosólicos a serem reciclados formando corpos multivesiculares (Mijaljica et al., 2011).

A invaginação do vacúolo microautofágico mostrou-se mediada pela proteína calmodulina em uma função independente de $\mathrm{Ca}^{2+}$, independente da maquinaria de fusão vacuolar, sensível à temperatura (Uttenweiler et al., 2005), dependente de ATP e microfilamentos, assim, estados de inanição diminuem o tunover de proteínas (Jianhua Zhang, 2015).

Alguns autores classificam a microautofagia em não seletiva e seletiva. Nesta, realiza-se englobamentos de organelas através de um processo eletroestático de aproximação mediado por HSC70 e é dependente dos complexos de classificação endossômica necessários para o transporte do tipo I e III (ESCRT I e III) que são responsáveis pela formação das vesículas em endossomos tardios (Sahu et al., 2011). Micromitofagia (reciclagem de componentes mitocondriais), micronucleofagia (reciclagem de componentes nucleares) e micropexofagia (fusão de peroxissomos), são subclassificações da microautofagia seletiva de acordo com a organela alvo (Mijaljica et al., 2011). 
A autofagia mediada por chaperona (CMA) é o processo de degradação de proteínas específicas que contenham um motivo pentapeptídico KFERQ exposto, isto ocorre quando determinadas proteínas estão danificadas ou mal dobradas, e a necessidade de tal motivo é obrigatória.

O reconhecimento da sequência é realizado pela proteína de choque térmico de $70 \mathrm{kDa}$ (HSC70) no citosol, que transporta a proteína a ser degradada até a superfície do lisossomo, onde o complexo proteína-chaperona interage com a LAMP-2A (Proteína de membrana associada ao lisossoma tipo 2A) no seu domínio citosólico. A doravante, a proteína a ser degradada sofre um processo de desdobramento, exclusivo da CMA, e no lúmen interage com outra forma de HSC70, que ajuda em sua translocação, após, a proteína é rapidamente degradada. Acredita-se que a regulação da CMA é realizada pelos níveis de LAMP-2A na membrana lisossomal. Condições como inanição e estresse oxidativo aumentam a transcrição gênica e tradução da LAMP-2A. Ademais, o processo de ativação da CMA necessita de um período maior de privação nutricional, cerca de 10 horas e continua ativo por até 72 horas, em contraste a micro e macroautofagia que podem se iniciar em cerca de 30 minutos em condições adversas(Sureshbabu et al., 2015),(Kaushik et al., 2011).

A macroautofagia (MA) é o processo com maior capacidade de reciclagem de proteínas e melhor estudado. Envolve cerca de 36 proteínas ATG reconhecidas em S. cerevisiae e grande parte apresentou homólogos em mamíferos, lembrando que o campo de estudo ainda é crescente(Sureshbabu et al., 2015),(Jianhua Zhang, 2015).

As cinco etapas principais da MA podem ser elencadas sequencialmente em processo de formação do fagófaro (1), expansão da membrana de isolamento do fagófaro e abastecimento de carga (2), conclusão da formação do fagófaro maduro (autofagossoma) (3), fusão entre o autofagossoma e o lisossoma (4), e finalmente a degradação do autofagolisossoma ou extrusão (5)(R. Kang et al., 2011),(Sureshbabu et al., 2015).

A MA é regulada por duas vias principais; uma via que envolve o complexo enzimático mTORC1 (do qual a cinase mTOR participa), e uma via que envolve a AMPK (AMP-activated protein kinase) (Wirth et al., 2013)'(Russell et al., 2014). Estudos demostraram que esta regulação ocorre devido a uma fosforilação da proteína serina/treonina cinase ULK1 pela mTORC1 e pela PKA. A ULK1 que é encontrada em complexo com as proteínas Atg13 (Autophagy-related protein 13), FIP200 (FAK family kinase-interacting protein of $200 \mathrm{kDa}$ ) e ATG101 (Autophagy-related protein 101). A mTORC1 também hiperfosfoforila a Atg13 diminuindo sua afinidade pela ULK1(Wirth et al., 2013),(Ganley et al., 2009).

Para a formação do fagófaro, a ULK1 desfosforilada, pela inativação da mTORC1, dissocia-se e fosforila a proteína Atg13, a FIP200 e a RB1CC1 (RB1 Inducible Coiled-Coil 1) iniciando a nucleação(Hale et al., 2013),(Ganley et al., 2009),(Y. Lee et al., 2017).

A proteína cinase ULK1 fosforila um complexo enzimático (PIK3C3/VPS34-Atg14L) ativando-o, e esse complexo recruta a proteína regulatória BECLIN1(Hale et al., 2013),(Y. Lee et al., 2017). Após, o complexo formado (PIK3C3/VPS34-Atg14Lp150-NRBF2-BECLIN1) se liga à membrana e começa a fosforilar os lipídios de membrana fosfatidilinositol gerando fosfatidilinositol-3-fosfato (PI3P); este por sua vez interage com a proteína WIPI (proteína de interação de fosfoinositídeo de domínio de repetição WD) controlando a expansão da membrana de isolamento(Nakatogawa, 2020).

O complexo WIPI-Atg2 se colocaliza com a proteína transmembrana Atg9 (Autophagy-related protein 9), encontrada em vesículas citoplasmáticas e aglomerados tubovesiculares advindos do Golgi ou endossomos, mediando assim a translocação de fosfolipídios da parte externa para o lúmen(Matoba et al., 2020),(Nakatogawa, 2020). O PI3P também serve de ancoragem para outro complexo enzimático, o Atg21/WIPI2b responsável pela interação com a proteína Atg16 (Autophagy-related protein 16).

A proteína Atg16 é participa de uma via de conjugação de ubiquitina formando pela interação com Atg5 (Autophagy-related protein 5)., que por sua vez, se conjuga a Atg12 (Autophagy-related protein 12). A proteína Atg12, semelhante à ubiquitina, é ativada pela enzima Atg7 em seu grupo C-terminal utilizando ATP. A enzima Atg10 catalisa a reação de ligação isopeptídica 
em um resíduo de lisina da Atg5. O pré-complexo Atg12-Atg5 interage com Atg16, formando o complexo Atg12-Atg5Atg16(Nakatogawa, 2020),(Hale et al., 2013).

A outra via de conjugação semelhante à ubiquitina é a via das proteínas da família homólogas à Atg8, representadas em mamíferos pelas proteínas associadas aos microtúbulos 3 (MAP1LC3), proteínas associadas ao receptor GABA (GABARAPS) e intensificador de ATPase associado ao Golgi (GATE16)(Jianhua Zhang, 2015). Estas proteínas, logo após sua expressão, estão sujeitas a clivagem pela protease Atg4 (formando LC3-1), que expõe seus resíduos de glicina no C-terminal. Doravante, a Atg7 age ativando o C-terminal utilizando ATP, o Atg3 conjuga a LC3/Atg8 (formando o LC3-II) e o encaminha para a Atg16 que finaliza conjugando essas proteínas à fosfatidiletanolamina (Nakatogawa, 2020),(Hale et al., 2013),(Sureshbabu et al., 2015),(H. He et al., 2003). A Atg4 ainda é responsável pela delipidação de Atg8 e esta função é inibida pela fosforilação por ULK1.

As possíveis fontes de membrana destinadas ao processo de autofagia são o retículo endoplasmático, complexo de Golgi e endossomos reciclados. A sinalização autofágica inicia o processo com a fosforilação de fosfatidilinositol a PI3P, sinalizando a ligação com Atg2-WIPI e o recrutamento de vesículas. Outro mecanismo é a formação de vesículas COPII no retículo endoplasmático, seu processamento no Golgi e fusão no autofagossoma por meio de proteínas SNAREs (Nakatogawa, 2020).

A aquisição de carga ocorre por meio da ligação entre proteínas ubiquitinadas, proteinas adaptadoras e cauda LC3-II. As proteínas adaptadoras responsáveis por ligação ao complexo ubiquitinado, descobertas até o momento, são a p62/SQSTM1 (sequestossomo 1), NBR1, NDP53, e Optneurina (Rogov et al., 2014),(Kumsta et al., 2019).

Os processos descritos auxiliam na formação do ômegassoma, estrutura semelhante à letra grega ômega em um corte sagital (Axe et al., 2008), porém, os exatos mecanismos que concernem à formação do autofagossoma ainda são desconhecidos. Acredita-se que aAtg16 e a Atg8 lipidada são responsáveis pela formação da curvatura, e as proteínas Atg20 e Atg24 se ligam ao PI3P, por um domínio PX, estabilizando a curvatura do autofagossoma(Nakatogawa, 2020). A membrana se dobra formando uma esfera e um único poro permanece, sendo necessário seu fechamento. Estudos indicam que este fechamento é realizado pelo complexo ESCRT-III (endosomal sorting complexes required for transport III); outros componentes também podem estar envolvidos, como ESCRT-0, ESCRT-I e ESCRT-II, Atg17, Vps4 e Vps21(Zhou et al., 2019).

As enzimas lisossomais necessárias para a digestão dentro do autofagossoma são adquiridas após a fusão com um lisossoma citoplasmático. Esta fusão ocorre através de um processo que necessita de microtúbulos e das proteínas MEN2, Tecpr1, presenlinas, DRAM1, miosina, Tom 1 e PLEKHM1. A proteína sintaxina SNARE 17 (STX17), na membrana autofagossômica, liga-se ao SNAP29 e complexa-se com a VAMP7/8 do lisossoma mediando a fusão das membranas(Itakura et al., 2012),(McEwan et al., 2015),(X. D. Zhang et al., 2013),(Tumbarello et al., 2012),(Jianhua Zhang, 2015).

As mitocôndrias que estão danificadas ou despolarizadas também são direcionadas seletivamente aos autofagossomas. Esse processo é mediado por ubiquitina ligada às proteínas adaptadoras optneurina, sequestossoma/p62, NDP52, porém existem vias independentes de ubiquitina que utilizam NIX/BNIP3L, FUNDC1, AMBRA1, Bcl-2-L-13, e PHB2(Cen et al., 2020). A ubiquitinação mitocondrial ocorre pela ação da enzima ubiquitina ligase E3 (Parkin/PARK2) que é recrutada pela proteína cinase mitocondrial PINK1, que em estados fisiológicos normais é processada pela PARL e permanece inativa. Em estados de disfunção mitocondrial a PARL é inativada permitindo que PINK1 recrute PARK2, fosforize-o e ative sua função de ubiquitina ligase. Após, ocorre a ligação entre proteínas adaptadoras, ubiquitina e o LC3-II, levando a organela para digestão (Durcan \& Fon, 2015).

\section{Regulação da autofagia}

A regulação fina da autofagia fica a cargo de dois sensores do metabolismo energético e nutricional, as proteínas cinase mTOR e AMPK, que estão intrinsicamente ligadas à inativação e ativação da ULK1, respectivamente (Holczer et al., 2020). 
A via mTORC1 representa uma via anabólica regulada por inanição, privação de fatores de crescimento, diminuição de ATP, hipóxia e espécies reativas de oxigênio. A sinalização de aminoácidos vinda do lúmen lisossomal transloca o complexo mTORC1, formado pela mTOR, um regulador (p18, p14 e MP51) e uma RagGTPase, que interage com o homologo da Rheb (Ras homolog enriched in brain) e ativa a via à jusante fosforizando a ULK1 e Atg13. A inanição leva à dissociação da mTOR do lisossomo. A privação de fatores de crescimento leva a uma inativação da enzima cinase Akt, que por sua vez não fosforiza as proteínas TSC1 e TSC2 (Tuberous sclerosis 1 e 2), permitindo a interação TSC1/TSC2,que inibe a mTOR e a Rheb (Inoki et al., 2002),(Bar-Peled et al., 2012).

A depleção de ATP, em decorrência de uma diminuição da glicose, ativa a AMPK, que regula a ação da mTOR, ativa a ULK1 e também o complexo TSC1/TSC2, estimulando, assim, a autofagia. A ativação do fator de transcrição TFEB também inibe a via mTORC1(Jianhua Zhang, 2015) A hipóxia medeia uma inativação da mTORC1 pelas alterações mitocondriais e aumento na transcrição de HIFa que estimula a produção de Bnip3, uma proteína da família Bcl-2 responsável por inibir a Rheb (Li et al., 2007). As espécies reativas de oxigênio também exercem efeito sobre a via mTOR, a expressão da proteína PEX5 e PEX19 pelos peroxissomas exerce uma ativação na proteína TSC2, que por sua vez, inibe a mTORC1 (Jiangwei Zhang et al., 2013).

A proteína Beclin-1 também sofre regulação e interfere na via da autofagia. Em estados normais ela encontra-se associada à proteína Bcl-2 e tem sua função suprimida. Estudos recentes demonstraram que a atividade física de até 15 minutos, reduz esta ligação e ativa a via autofágica(C. He et al., 2012). Além disso, a Beclin-1 pode associar-se a dois complexos cruciais na autofagia - o complexo PIK3C3/VPS34-Atg14L-p150-NRBF2-BECLIN1 e o complexo UVRAG-SH3GLB1/BIF1-PIK3C3PIK3R4/VPS15-BECN1. Além disso, a associação com o regulador 1 de Beclin (AMBRA1) estimula a autofagia, e a sua associação com a proteína Rubicon regula negativamente a autofagia. A Figura 1 demonstra as principais relações regulatórias da autofagia e seus efetores.

Figura 1. Principais vias regulatórias da autofagia. Setas indicam ativação e traços inibição.

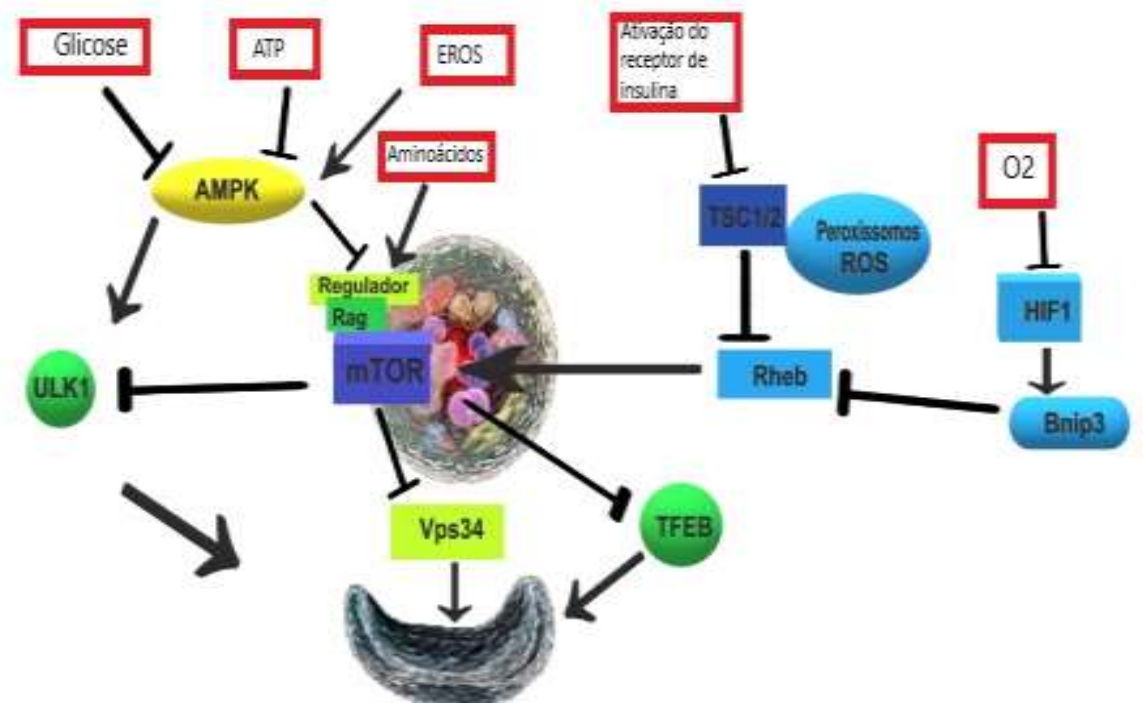

Fonte: Autores (2020). 


\section{Discussão}

A função da autofagia no desenvolvimento do câncer apresenta vários mecanismos que explicam seu efeito protetor, desde o aumento do tunover de antígenos e processamento, aumento da transcrição e ativação de genes supressores tumorais até a degradação de proteínas obsoletas e mitocôndrias disfuncionais. Em contraste, a autofagia também pode mediar um processo de resistência tumoral em estágios avançados, como um mecanismo de sobrevivência em condições extremas (Levy et al., 2017),(Vanzo et al., 2019).

Hoje, é consenso que a autofagia apresenta uma via supressora tumoral, que pode ser usada de maneira profilática, e uma via envolvida em processo de sobrevivência de células tumorais e resistência a drogas(Rubinsztein et al., 2012).

No início da tumorogênese algumas proteínas envolvidas na autofagia são consideradas, com determinada solidez, supressores tumorais. Entre elas encontram-se a Beclin-1, TSC1/2, Atg4, Atg5, Atg7, PARK2, LKB1 e p62, além disso, a inibição de mTOR, degradação mitocondrial e regulação de Bcl-2 está envolvida na diminuição da incidência de câncer (Jianhua Zhang, 2015),(Rubinsztein et al., 2012),(C. He et al., 2012).

A proteína Beclin-1 é descrita no desenvolvimento de tumores de próstata, mama, ovário e bexiga. Ela se encontra ligada à proteína anti-apoptótica Bcl-2, e esta ligação inibe suas funções na autofagia e na ativação da enzima AMPK. Sua ação antitumoral ainda é controversa, mas propõe-se que a inibição de vias de proliferação celular, como a Akt e mTOR, sejam responsáveis por tal (Yue et al., 2003).

As proteínas TSC1/2 são classicamente denotadas como supressoras tumorais por inibirem mTORC1 e impedirem o crescimento celular. Elas estão intimamente envolvidas na ativação da autofagia e respondem à produção de espécies reativas de oxigênio que ativam a proteína ATM (Ataxia Telangiectasia Mutada), um sensor do ciclo celular, e este interage com TSC2 (Alexander et al., 2010).

As Atg5 e Atg7 foram estudas no desenvolvimento de tumores e sua supressão acarreta é uma maior taxa de mutações de DNA levando à carcinogênese de células hepáticas, assim, indicando que a autofagia apresenta um papel considerável na supressão tumoral (Takamura et al., 2011).

O gene supressor de tumor amplamente envolvido no desenvolvimento de câncer, p53, também exerce papel na autofagia, o qual depende de sua localização e estado de fosforilação para mediar essas repostas. Quando presente no núcleo, p53 aumenta a transcrição de fatores autofágicos e incita via, quando no citoplasma, causa uma inibição da autofagia por se ligar ao complexo RB1CC1/FIP200 (Morselli et al., 2011).

A enzima E3 ligase (PRAK2), envolvida na mitofagia, foi descrita como supressora tumoral por reciclar mitocôndrias danificadas e evitar agressão ao DNA por espécies reativas de oxigênio. Mutações nesse gene comumente geram tumores de cólon, pulmão e no sistema nervoso central(Poulogiannis et al., 2010),(Mhatre V. Ho and Kelsey C. Martin, 2012). A autofagia também se mostrou protetora por consumir proteínas adaptadoras utilizadas na progressão do ciclo celular. É o caso da p62, onde em células hepáticas tumorais a eliminação de p62 reduz a progressão do carcinoma hepatocelular (Takamura et al., 2011).

Mutações no gene do fator associado à resistência à radiação UV (UVRAG), utilizado na maturação do autofagossoma, foi relacionado a um aumento da inflamação e da tumorigênese, demonstrando a importância da autofagia na prevenção do câncer (Quach et al., 2019).

O sistema de autofagia, em estados em que o tumor já se desenvolveu, acarreta em manutenção das células tumorais à privação de nutrientes. Alterações heterozigóticas em Beclin-1 demonstraram aumento na porcentagem de tumores malignos, devido a um aumento da capacidade de sobrevivência celular. HIF-alfa e a RAS são inicialmente estimuladas para evitar os danos causados pelo microambiente e promovem a autofagia, que pode parar a progressão tumoral; quando não são estimuladas, 
estas vias podem estimular a transcrição de oncogenes, perpetuando assim a célula tumoral(Vanzo et al., 2019),(Rubinsztein et al., 2012).

\section{Atividade física e redução do câncer}

Em um grande estudo prospectivo foi demonstrado que a atividade física reduz a incidência de 13 tipos diferentes de câncer. O estudo multicêntrico de 11 anos, com uma população de 1,65 milhões de pessoas, demostrou uma redução média de $20 \%$ na incidência de diversos tipos de câncer, com melhores índices com maior carga de atividade física. Adenocarcinoma de esôfago, tumores hepáticos, de pulmão, rim, cárdia gástrica, endométrio, cólon, cabeça e pescoço, retal, bexiga, mama, leucemia e mieloma demonstraram-se diminuídos com resultados sólidos e IC (índice de confiabilidade) de 95\%(Moore et al., 2017).

A fisiologia da redução do câncer é complexa e envolve ativação da autofagia(Halling \& Pilegaard, 2017), redução de sinais de crescimento celular(Hojman et al., 2017), modulação imune(Koelwyn et al., 2020),(Ortega et al., 1998), diminuição da inflamação(D. W. Kang et al., 2017), redução da insulina basal(S. Lee et al., 2018), realocação e ativação de p53(Beyfuss et al., 2018) e ativação da via AMPK(Hojman et al., 2017).

\section{Conclusão}

Este trabalho visa elencar os mecanismos pelo qual a atividade física ativa a autofagia e em quais via ela age para impedir o desenvolvimento de tumores. Ao correlacionar os mecanismos pelos quais a autofagia é recrutada é possível estabelecer

1) A via mTORC1 é sensível à privação de nutrientes(Jianhua Zhang, 2015). As alterações metabólicas e distributivas alteram o fluxo sanguíneo(Ichinose et al., 2014),(Nobrega et al., 2014) e disponibilidade de nutrientes(Lundsgaard et al., 2020). Estes efeitos não se restringem ao músculo ativo, então, conclui-se que a autofagia é aumentada em todo o corpo. A inanição faz com que a mTOR dissocie-se do complexo mTORC1, inibindo a via à jusante (Bar-Peled et al., 2012). Parte desta diminuição de aporte nutricional é explicada pela resistência à insulina transitória e diminuição deste hormônio (Kraemer et al., 1998),(David H. Wasserman, 2009),(D. H. Wasserman et al., 1989). Glucagon(Ahlborg et al., 1974), folistatina, FGF21(Murphy et al., 2020) são liberados durante a atividade física, e como resistores, inibem a ativação dos receptores de fatores de crescimento. Isso leva à uma inativação da Akt que por sua vez não fosforila as proteínas TSC1 e TSC2, permitindo a interação TSC1/TSC2, a qual inibe inibe a mTOR e a Rheb (Inoki et al., 2002),(Bar-Peled et al., 2012). A depleção de ATP em decorrência de uma diminuição de glicose, devido ao desvio do fluxo sanguíneo, diminuição sérica e diminuição da permeabilidade, ativa a AMPK, que regula a ação de mTOR, ativa a ULK1 e também a TSC1/TSC2, estimulando, assim, a autofagia. A ativação do fator de transcrição TFEB também inibe a via mTORC1(Jianhua Zhang, 2015). Além disso, a insulina e IGF, estimuladores do crescimento celular, encontram-se reduzidos em pacientes que praticam atividade física regularmente, demonstrando um aumento da sensibilidade à insulina pós atividade física(D. W. Kang et al., 2017)(Figura 2). 
Figura 2. O exercício físico causa mudanças hormonais e oxidativas no organismo (setas azuis e vermelhas), levando a alterações celulares energéticas e mitocondriais (setas verdes), ativando e inativando vias (setas amarelas) que resultam em estimula da autofagia.

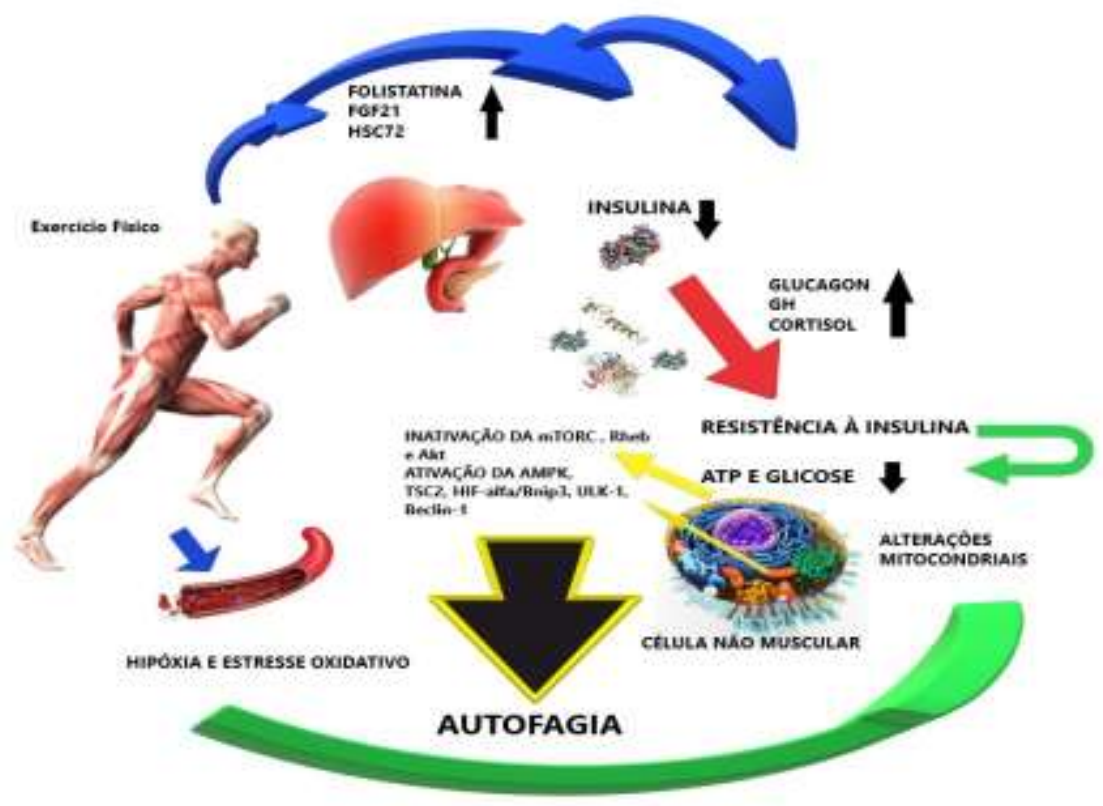

Fonte: Autores (2020).

2) As espécies reativas de oxigênio e a hipóxia gerada pela atividade física também inativam a mTORC1. As espécies reativas de oxigênio exercem efeito sobre a via mTOR; a expressão da proteína PEX5 e PEX19 pelos peroxissomas exerce uma ativação na proteína TSC2, que por sua vez inibe a mTORC1(Qiao et al., 2015),(Jiangwei Zhang et al., 2013). A hipóxia medeia uma inativação da mTORC1 pela as alterações mitocondriais e aumento na transcrição de HIFa, que estimula a produção de Bnip3, uma proteína da família Bcl-2 responsável por inibir a Rheb (Li et al., 2007).

3) Regulação da autofagia por vias alternativas à mTORC1. Acredita-se que a atividade física pode desencadear a autofagia por vias não centrais com a prática crônica de exercícios(Y. Lee et al., 2017). A autofagia pode ser recrutada independentemente da mTOR através do receptor canabinóide CB1, e mediada por trealose (Wu et al., 2014),(Y. L. Kang et al., 2014). O exercício físico também causa alterações na ativação e localização de p53. No exercício agudo esta proteína na forma fosforilada aumenta no núcleo estimulando a transcrição de genes relacionados à autofagia, e posteriormente sua concentração citoplasmática aumenta; porém, ela é dirigida para a mitocôndria interagindo com o fator de transcrição mitocondrial- Tfam, e aumentando a biogênese mitocondrial (Beyfuss et al., 2018), (Morselli et al., 2011). A interação do DNA mitocondrial com o receptor Toll Like 9 (TLR9) age ativando a via AMPK e auxiliando no ativação dos complexos dependentes de Beclin-1(Liu et al., 2020). E por último, as sestrinas- proteínas induzidas por estresse - ativam fortemente a autofagia via AMPK, melhorando a sensibilidade à insulina, além de apresentarem efeitos antioxidantes no organismo (Kim et al., 2020).

A presente revisão apresenta dados promissores, abrindo espaço para elaboração de estudos clínicos futuros, sejam visando a prevenção primária e promoção de saúde quanto a intervenção externa com modulação dos alvos moleculares demonstrados 
acima. Além disso, hoje é possível a delineação de proteínas através de softwares e aplicação das mesmas em modelos murinos, a utilização de moléculas como a sestrina para regulação da autofagia seria elucidador e uma possível linha de prevenção do câncer.

À luz do exposto fica demonstrando a ímpar relevância da atividade física no desenvolvimento do câncer. A literatura científica respalda os achados epidemiológicos com a descrição molecular dos mecanismos envolvidos, revelando que o sedentarismo, isolado, é um importante fator de risco para tumorogênese e diversas outras patologias.

\section{Referências}

Ahlborg, G., Felig, P., Hagenfeldt, L., Hendler, R., \& Wahren, J. (1974). Substrate turnover during prolonged exercise in man. Splanchnic and leg metabolism of glucose, free fatty acids, and amino acids. Journal of Clinical Investigation, 53(4), 1080-1090. https://doi.org/10.1172/JCI107645

Alexander, A., Cai, S. L., Kim, J., Nanez, A., Sahin, M., MacLean, K. H., Inoki, K., Guan, K. L., Shen, J., Person, M. D., Ku sewitt, D., Mills, G. B., Kastan, M. B., \& Walker, C. L. (2010). ATM signals to TSC2 in the cytoplasm to regulate mTORC1 in response to ROS. Proceedings of the National Academy of Sciences of the United States of America, 107(9), 4153-4158. https://doi.org/10.1073/pnas.0913860107

Andriolo, V., Dietrich, S., Knüppel, S., Bernigau, W., \& Boeing, H. (2019). Traditional risk factors for essential hypertension: analysis of their specific combinations in the EPIC-Potsdam cohort. Scientific Reports, 9(1), 1-10. https://doi.org/10.1038/s41598-019-38783-5

Aulianida, D., Liestyasari, S. I., \& Ch, S. R. (2003). Cem Bilhões de Neurônios. In Journal of Chemical Information and Modeling (Vol. 53, Issue 9).

Axe, E. L., Walker, S. A., Manifava, M., Chandra, P., Roderick, H. L., Habermann, A., Griffiths, G., \& Ktistakis, N. T. (2008). Autophagosome formation from membrane compartments enriched in phosphatidylinositol 3-phosphate and dynamically connected to the endoplasmic reticulum. Journal of Cell Biology, 182(4), 685-701. https://doi.org/10.1083/jcb.200803137

Bar-Peled, L., Schweitzer, L. D., Zoncu, R., \& Sabatini, D. M. (2012). Ragulator is a GEF for the rag GTPases that signal amino acid levels to mTORC1. Cell, 150(6), 1196-1208. https://doi.org/10.1016/j.cell.2012.07.032

Beyfuss, K., Erlich, A. T., Triolo, M., \& Hood, D. A. (2018). The Role of p53 in Determining Mitochondrial Adaptations to Endurance Training in Skeletal Muscle. Scientific Reports, 8(1), 1-14. https://doi.org/10.1038/s41598-018-32887-0

Blair, S. N., LaMonte, M. J., \& Nichaman, M. Z. (2004). The evolution of physical activity recommendations: how much is enough? The American Journal of Clinical Nutrition, 79(5), 913-920. https://doi.org/10.1093/ajcn/79.5.913s

Brambilla, P., Pozzobon, G., \& Pietrobelli, A. (2011). Physical activity as the main therapeutic tool for metabolic syndrome in childhood. International Journal of Obesity, 35(1), 16-28. https://doi.org/10.1038/ijo.2010.255

Cassilhas, R. C., Tufik, S., \& De Mello, M. T. (2016). Physical exercise, neuroplasticity, spatial learning and memory. Cellular and Molecular Life Sciences, 73(5), 975-983. https://doi.org/10.1007/s00018-015-2102-0

Cen, X., Chen, Y., Xu, X., Wu, R., He, F., Zhao, Q., Sun, Q., Yi, C., Wu, J., Najafov, A., \& Xia, H. (2020). Pharmacological targeting of MCL-1 promotes mitophagy and improves disease pathologies in an Alzheimer's disease mouse model. Nature Communications, 11(1). https://doi.org/10.1038/s41467-020$19547-6$

Chen, X., Wang, Q., Zhang, Y., Xie, Q., \& Tan, X. (2019). Physical Activity and Risk of Breast Cancer: A Meta-Analysis of 38 Cohort Studies in 45 Study Reports. Value in Health, 22(1), 104-128. https://doi.org/10.1016/j.jval.2018.06.020

Coggan, A. R., Swanson, S. C., Mendenhall, L. A., Habash, D. L., \& Kien, C. L. (1995). Effect of endurance training on hepatic glycogenolysis and gluconeogenesis during prolonged exercise in men. American Journal of Physiology - Endocrinology and Metabolism, 268(3 31-3). https://doi.org/10.1152/ajpendo.1995.268.3.e375

Durcan, T. M., \& Fon, E. A. (2015). USP8 and PARK2/parkin-mediated mitophagy. Autophagy, 11(2), 428-429. https://doi.org/10.1080/15548627.2015.1009794

Elizabeth, Q. (1957). Supine Leg Exercise. 1942, 294-308.

Fritzen, A. M., Madsen, A. B., Kleinert, M., Treebak, J. T., Lundsgaard, A. M., Jensen, T. E., Richter, E. A., Wojtaszewski, J., Kiens, B., \& Frøsig, C. (2016). Regulation of autophagy in human skeletal muscle: Effects of exercise, exercise training and insulin stimulation. Journal of Physiology, 594(3), 745-761. https://doi.org/10.1113/JP271405

Ganley, I. G., Lam, D. H., Wang, J., Ding, X., Chen, S., \& Jiang, X. (2009). ULK1·ATG13·FIP200 complex mediates mTOR signaling and is essential for autophagy. Journal of Biological Chemistry, 284(18), 12297-12305. https://doi.org/10.1074/jbc.M900573200

Guyton \& Hall. (2011). Tratado de Fisiologia - Guyton $12^{a}$ Edição.pdf (p. 1176).

Hale, A. N., Ledbetter, D. J., Gawriluk, T. R., \& Rucker, E. B. (2013). Autophagy: Regulation and role in development. Autophagy, 9(7), 951-972. https://doi.org/10.4161/auto.24273

Halling, J. F., \& Pilegaard, H. (2017). Autophagy-Dependent Beneficial Effects of Exercise. Cold Spring Harbor Perspectives in Medicine, 7(8), 1-13. 
https://doi.org/10.1101/cshperspect.a029777

Hanakawa, T., Immisch, I., Toma, K., Dimyan, M. A., Van Gelderen, P., \& Hallett, M. (2003). Functional properties of brain areas associated with motor execution and imagery. Journal of Neurophysiology, 89(2), 989-1002. https://doi.org/10.1152/jn.00132.2002

Hansen, J. S., Pedersen, B. K., Xu, G., Lehmann, R., Weigert, C., \& Plomgaard, P. (2016). Exercise-induced secretion of FGF21 and follistatin are blocked by pancreatic clamp and impaired in type 2 diabetes. Journal of Clinical Endocrinology and Metabolism, 101(7), 2816-2825. https://doi.org/10.1210/jc.2016-1681

Hardwick, R. M., Rottschy, C., Miall, R. C., \& Eickhoff, S. B. (2013). A quantitative meta-analysis and review of motor learning in the human brain. NeuroImage, 67, 283-297. https://doi.org/10.1016/j.neuroimage.2012.11.020

Hargreaves, M., \& Spriet, L. L. (2020). Skeletal muscle energy metabolism during exercise. Nature Metabolism, 2(9), 817-828. https://doi.org/10.1038/s42255020-0251-4

Harrison, D. G., Widder, J., Grumbach, I., Chen, W., Weber, M., \& Searles, C. (2006). Endothelial mechanotransduction, nitric oxide and vascular inflammation. Journal of Internal Medicine, 259(4), 351-363. https://doi.org/10.1111/j.1365-2796.2006.01621.x

Hawley, J. A., Hargreaves, M., Joyner, M. J., \& Zierath, J. R. (2014). Integrative biology of exercise. Cell, 159(4), 738-749. https://doi.org/10.1016/j.cell.2014.10.029

Haydon, A. M. M., MacInnis, R. J., English, D. R., \& Giles, G. G. (2006). Effect of physical activity and body size on survival after diagnosis with colorectal cancer. Gut, 55(1), 62-67. https://doi.org/10.1136/gut.2005.068189

He, C., Bassik, M. C., Moresi, V., Sun, K., Wei, Y., Zou, Z., An, Z., Loh, J., Fisher, J., Sun, Q., Korsmeyer, S., Packer, M., May, H. I., Hill, J. A., Virgin, H. W., Gilpin, C., Xiao, G., Bassel-Duby, R., Scherer, P. E., \& Levine, B. (2012). Exercise-induced BCL2-regulated autophagy is required for muscle glucose homeostasis. Nature, 481(7382), 511-515. https://doi.org/10.1038/nature10758

He, H., Dang, Y., Dai, F., Guo, Z., Wu, J., She, X., Pei, Y., Chen, Y., Ling, W., Wu, C., Zhao, S., Liu, J. O., \& Yu, L. (2003). Post-translational modifications of three members of the human MAP1LC3 family and detection of a novel type of modification for MAP1LC3B. Journal of Biological Chemistry, 278(31), 29278-29287. https://doi.org/10.1074/jbc.M303800200

Hojman, P., Gehl, J., Christensen, J. F., \& Pedersen, B. K. (2017). Molecular Mechanisms Linking Exercise to Cancer Prevention and Treatment. Cell Metabolism, 27(1), 10-21. https://doi.org/10.1016/j.cmet.2017.09.015

Holczer, M., Hajdú, B., Lőrincz, T., Szarka, A., Bánhegyi, G., \& Kapuy, O. (2020). Fine-tuning of AMPK-ULK1-mTORC1 regulatory triangle is crucial for autophagy oscillation. Scientific Reports, 10(1), 1-12. https://doi.org/10.1038/s41598-020-75030-8

Ichinose, M., Maeda, S., Kondo, N., \& Nishiyasu, T. (2014). Blood pressure regulation II: What happens when one system must serve two masters - Oxygen delivery and pressure regulation? European Journal of Applied Physiology, 114(3), 451-465. https://doi.org/10.1007/s00421-013-2691-y

Inoki, K., Li, Y., Zhu, T., Wu, J., \& Guan, K. L. (2002). TSC2 is phosphorylated and inhibited by Akt and suppresses mTOR signalling. Nature Cell Biology, 4(9), 648-657. https://doi.org/10.1038/ncb839

Itakura, E., Kishi-Itakura, C., \& Mizushima, N. (2012). The hairpin-type tail-anchored SNARE syntaxin 17 targets to autophagosomes for fusion with endosomes/lysosomes. Cell, 151(6), 1256-1269. https://doi.org/10.1016/j.cell.2012.11.001

Kang, D. W., Lee, J., Suh, S. H., Ligibel, J., Courneya, K. S., \& Jeon, J. Y. (2017). Effects of exercise on insulin, IGF axis, adipocytokines, and inflammatory markers in breast cancer survivors: A systematic review and meta-analysis. Cancer Epidemiology Biomarkers and Prevention, 26(3), 355-365. https://doi.org/10.1158/1055-9965.EPI-16-0602

Kang, R., Zeh, H. J., Lotze, M. T., \& Tang, D. (2011). The Beclin 1 network regulates autophagy and apoptosis. Cell Death and Differentiation, 18(4), 571580. https://doi.org/10.1038/cdd.2010.191

Kang, Y. L., Saleem, M. A., Chan, K. W., Yung, B. Y. M., \& Law, H. K. W. (2014). Trehalose, an mTOR independent autophagy inducer, alleviates human podocyte injury after puromycin aminonucleoside treatment. PLOS ONE, 9(11), 1-9. https://doi.org/10.1371/journal.pone.0113520

Kaushik, S., Bandyopadhyay, U., Sridhar, S., Kiffin, R., Martinez-Vicente, M., Kon, M., Orenstein, S. J., Wong, E., \& Cuervo, A. M. (2011). Chaperonemediated autophagy at a glance. Journal of Cell Science, 124(4), 495-499. https://doi.org/10.1242/jcs.073874

Kim, M., Sujkowski, A., Namkoong, S., Gu, B., Cobb, T., Kim, B., Kowalsky, A. H., Cho, C. S., Semple, I., Ro, S. H., Davis, C., Brooks, S. V., Karin, M., Wessells, R. J., \& Lee, J. H. (2020). Sestrins are evolutionarily conserved mediators of exercise benefits. Nature Communications, 11(1), 1-14. https://doi.org/10.1038/s41467-019-13442-5

Koelwyn, G. J., Zhuang, X., Tammela, T., Schietinger, A., \& Jones, L. W. (2020). Exercise and immunometabolic regulation in cancer. Nature Metabolism, 2(9), 849-857. https://doi.org/10.1038/s42255-020-00277-4

Kraemer, W. J., Haekkinen, K., Newton, R. U., McCormick, M., Nindl, B. C., Volek, J. S., Gotshalk, L. A., Fleck, S. J., Campbell, W. W., Gordon, S. E., Farrell, P. A., \& Evans, W. J. (1998). Acute hormonal responses to heavy resistance exercise in younger and older men. / Reponses hormonales aigues a un exercice important de resistance chez les hommes jeunes et vieux. European Journal of Applied Physiology \& Occupational Physiology, 77(3), 206-211. http://articles.sirc.ca/search.cfm?id=461991\%5Cnhttp://ezproxy.library.yorku.ca/login?url=http://search.ebscohost.com/login.aspx?direct=true\&db=sph\&AN= SPH461991\&site=ehost-live\%5Cnhttp://link.springer.de

Kumsta, C., Chang, J. T., Lee, R., Tan, E. P., Yang, Y., Loureiro, R., Choy, E. H., Lim, S. H. Y., Saez, I., Springhorn, A., Hoppe, T., Vilchez, D., \& Hansen, M. (2019). The autophagy receptor p62/SQST-1 promotes proteostasis and longevity in C. elegans by inducing autophagy. Nature Communications, 10(1), 5648. https://doi.org/10.1038/s41467-019-13540-4 
L. Brunton, L., Hilal-Dandan, R., \& C. Knollmann, B. (2012). Goodman \& Gilman 12 ${ }^{a}$ Ed., As Bases Farmacológicas da Terapêutica. 12.

Lee, S., Libman, I., Hughan, K., Kuk, J. L., Jeong, J. H., Zhang, D., \& Arslanian, S. (2018). Effects of Exercise Modality on Insulin Resistance and Ectopic Fat in Adolescents with Overweight and Obesity: A Randomized Clinical Trial. The Journal of Pediatrics, 206, 91-98.e1. https://doi.org/10.1016/j.jpeds.2018.10.059

Lee, Y., Kwon, I., Jang, Y., Song, W., Cosio-Lima, L. M., \& Roltsch, M. H. (2017). Potential signaling pathways of acute endurance exercise-induced cardiac autophagy and mitophagy and its possible role in cardioprotection. Journal of Physiological Sciences, 67(6), 639-654. https://doi.org/10.1007/s12576-017-0555-

Levine, B., Klionsky, D. J., Larsson, N.-G., \& Masucci, M. G. (2017). Scientific Background for the 2016 Nobel Prize in Physiology or Medicine. Proceedings of the National Academy of Sciences, 114(2), 201-205. https://doi.org/10.1073/pnas.1619876114

Levy, J. M. M., Towers, C. G., \& Thorburn, A. (2017). Targeting autophagy in cancer. Nature Reviews Cancer, 17(9), 528-542. https://doi.org/10.1038/nrc.2017.53

Li, Y., Wang, Y., Kim, E., Beemiller, P., Wang, C. Y., Swanson, J., You, M., \& Guan, K. L. (2007). Bnip3 mediates the hypoxia-induced inhibition on mammalian target of rapamycin by interacting with Rheb. Journal of Biological Chemistry, 282(49), 35803-35813. https://doi.org/10.1074/jbc.M705231200

Liu, Y., Nguyen, P. T., Wang, X., Zhao, Y., Meacham, C. E., Zou, Z., Bordieanu, B., Johanns, M., Vertommen, D., Wijshake, T., May, H., Xiao, G., ShojiKawata, S., Rider, M. H., Morrison, S. J., Mishra, P., \& Levine, B. (2020). TLR9 and beclin 1 crosstalk regulates muscle AMPK activation in exercise. Nature, 578(7796), 605-609. https://doi.org/10.1038/s41586-020-1992-7

Lundsgaard, A. M., Fritzen, A. M., \& Kiens, B. (2020). The importance of fatty acids as nutrients during post-exercise recovery. Nutrients, 12(2). https://doi.org/10.3390/nu12020280

Marin Bosch, B., Bringard, A., Logrieco, M. G., Lauer, E., Imobersteg, N., Thomas, A., Ferretti, G., Schwartz, S., \& Igloi, K. (2020). Effect of acute physical exercise on motor sequence memory. Scientific Reports, 10(1), 1-13. https://doi.org/10.1038/s41598-020-72108-1

Matoba, K., Kotani, T., Tsutsumi, A., Tsuji, T., Mori, T., Noshiro, D., Sugita, Y., Nomura, N., Iwata, S., Ohsumi, Y., Fujimoto, T., Nakatogawa, H., Kikkawa, M., \& Noda, N. N. (2020). Atg9 is a lipid scramblase that mediates autophagosomal membrane expansion. Nature Structural and Molecular Biology. https://doi.org/10.1038/s41594-020-00518-w

Matthews, C. E., Shu, X., Jin, F., Dai, Q., Hebert, J. R., Ruan, Z., Gao, Y., \& Zheng, W. (2001). Lifetime physical activity and breast cancer risk in the Shanghai Breast Cancer Study. 84, 994-1001.

Mayer, M. P., \& Bukau, B. (2005). Hsp70 chaperones: Cellular functions and molecular mechanism. Cellular and Molecular Life Sciences, 62(6), 670-684. https://doi.org/10.1007/s00018-004-4464-6

McConell, G. K., Sjøberg, K. A., Ceutz, F., Gliemann, L., Nyberg, M., Hellsten, Y., Frøsig, C., Kiens, B., Wojtaszewski, J. F. P., \& Richter, E. A. (2020). Insulin-induced membrane permeability to glucose in human muscles at rest and following exercise. Journal of Physiology, 598(2), 303-315. https://doi.org/10.1113/JP278600

McEwan, D. G., Popovic, D., Gubas, A., Terawaki, S., Suzuki, H., Stadel, D., Coxon, F. P., MirandadeStegmann, D., Bhogaraju, S., Maddi, K., Kirchof, A., Gatti, E., Helfrich, M. H., Wakatsuki, S., Behrends, C., Pierre, P., \& Dikic, I. (2015). PLEKHM1 regulates autophagosome-lysosome fusion through HOPS complex and LC3/GABARAP proteins. Molecular Cell, 57(1), 39-54. https://doi.org/10.1016/j.molcel.2014.11.006

Medbo, J. I., \& Tabata, I. (1993). Anaerobic energy release in working muscle during 30 s to 3 min of exhausting bicycling. Journal of Applied Physiology, 75(4), 1654-1660. https://doi.org/10.1152/jappl.1993.75.4.1654

Mhatre V. Ho and Kelsey C. Martin, J.-A. L. (2012). Somatic mutations of the Parkinson's disease-associated gene PARK2 in glioblastoma and other human malignancies. Bone, 23(1), 1-7. https://doi.org/10.1038/ng.491.Somatic

Michelini, L. C., O’Leary, D. S., Raven, P. B., \& Nóbrega, A. C. L. (2015). Neural control of circulation and exercise: A translational approach disclosing interactions between central command, arterial baroreflex, and muscle metaboreflex. American Journal of Physiology - Heart and Circulatory Physiology, 309(3), H381-H392. https://doi.org/10.1152/ajpheart.00077.2015

Mijaljica, D., Prescott, M., \& Devenish, R. J. (2011). Microautophagy in mammalian cells: RevisitiMicroautophagy in mammalian cells: Revisiting a 40-yearold conundrumng a 40-year-old conundrum. Autophagy, 7(7), 673-682. https://doi.org/10.4161/auto.7.7.14733

Moore, S. C., I-Min Lee, M., Weiderpass, E., Campbell, P. T., Sampson, J. N., Kitahara, C. M., K., S. K., Arem, H., Sesso, H., Gonzalez, Amy Berrington de, P. H., Blair, C. K., Borch, K. B., Boyd, E., Check, D. P., Fournier, A., Freedman, N. D., Gunter, M., Johannson, M., Khaw, K.-T., ... Patel, A. V. (2017). Leisuretime physical activity and risk of 26 types of cancer in 1.44 million adults. Physiology \& Behavior, 176(10), 139-148. https://doi.org/10.1001/jamainternmed.2016.1548.Leisure-time

Moreira, T. S., Takakura, A. C., Damasceno, R. S., Falquetto, B., Totola, L. T., Sobrinho, C. R., Ragioto, D. T., \& Zolezi, F. P. (2011). Central chemoreceptors and neural mechanisms of cardiorespiratory control. Brazilian Journal of Medical and Biological Research, 44(9), 883-889. https://doi.org/10.1590/S0100$879 \times 2011007500094$

Morselli, E., Shen, S., Ruckenstuhl, C., Bauer, M. A., Mariño, G., Galluzzi, L., Criollo, A., Michaud, M., Maiuri, M. C., Chano, T., Madeo, F., \& Kroemer, G. (2011). p53 inhibits autophagy by interacting with the human ortholog of yeast Atg17, RB1CC1/FIP200. Cell Cycle, 10(16), 2763-2769. https://doi.org/10.4161/cc.10.16.16868

Murphy, R. M., Watt, M. J., \& Febbraio, M. A. (2020). Metabolic communication during exercise. Nature Metabolism, 2(9), 805-816. https://doi.org/10.1038/s42255-020-0258-X 
Nakatogawa, H. (2020). Mechanisms governing autophagosome biogenesis. Nature Reviews Molecular Cell Biology, 21(8), 439-458. https://doi.org/10.1038/s41580-020-0241-0

Nobrega, A. C. L., O’Leary, D., Silva, B. M., Marongiu, E., Piepoli, M. F., \& Crisafulli, A. (2014). Neural regulation of cardiovascular response to exercise: Role of central command and peripheral afferents. BioMed Research International, 2014. https://doi.org/10.1155/2014/478965

Ortega, E., Peters, C., Barriga, C., \& Lötzerich, H. (1998). A atividade física reduz o risco de câncer? Revista Brasileira de Medicina Do Esporte, 4(3), 81-86. https://doi.org/10.1590/s1517-86921998000300003

Parolin, M. L., Chesley, A., Matsos, M. P., Spriet, L. L., Jones, N. L., \& Heigenhauser, G. J. F. (1999). Regulation of skele tal muscle glycogen phosphorylase and PDH during maximal intermittent exercise. American Journal of Physiology - Endocrinology and Metabolism, 277(5 40-5). https://doi.org/10.1152/ajpendo.1999.277.5.e890

Poulogiannis, G., McIntyre, R. E., Dimitriadi, M., Apps, J. R., Wilson, C. H., Ichimura, K., Luo, F., Cantley, L. C., Wyllie, A. H., Adams, D. J., \& Arends, M. J. (2010). PARK2 deletions occur frequently in sporadic colorectal cancer and accelerate adenoma development in Apc mutant mice. Proceedings of the National Academy of Sciences of the United States of America, 107(34), 15145-15150. https://doi.org/10.1073/pnas.1009941107

Qiao, S., Dennis, M., Song, X., Vadysirisack, D. D., Salunke, D., Nash, Z., Yang, Z., Liesa, M., Yoshioka, J., Matsuzawa, S. I., Shirihai, O. S., Lee, R. T., Reed, J. C., \& Ellisen, L. W. (2015). A REDD1/TXNIP pro-oxidant complex regulates ATG4B activity to control stress-induced autophagy and sustain exercise capacity. Nature Communications, 6. https://doi.org/10.1038/ncomms8014

Quach, C., Song, Y., Guo, H., Li, S., Maazi, H., Fung, M., Sands, N., O’Connell, D., Restrepo-Vassalli, S., Chai, B., Nemecio, D., Punj, V., Akbari, O., Idos, G. E., Mumenthaler, S. M., Wu, N., Martin, S. E., Hagiya, A., Hicks, J., ... Liang, C. (2019). A truncating mutation in the autophagy gene UVRAG drives inflammation and tumorigenesis in mice. Nature Communications, 10(1). https://doi.org/10.1038/s41467-019-13475-w

Richardson, R. S. (2003). Oxygen transport and utilization: An integration of the muscle systems. American Journal of Physiology - Advances in Physiology Education, 27(1-4), 183-191. https://doi.org/10.1152/advan.00038.2003

Rodrigues, A. Z. C., Wang, Z. M., Messi, M. L., \& Delbono, O. (2019). Sympathomimetics regulate neuromuscular junction transmission through TRPV1, P/Qand N-type Ca 2+ channels. Molecular and Cellular Neuroscience, 95(February), 59-70. https://doi.org/10.1016/j.men.2019.01.007

Rogov, V., Dötsch, V., Johansen, T., \& Kirkin, V. (2014). Interactions between Autophagy Receptors and Ubiquitin-like Proteins Form the Molecular Basis for Selective Autophagy. Molecular Cell, 53(2), 167-178. https://doi.org/10.1016/j.molcel.2013.12.014

Romijn, J. A., Coyle, E. F., Sidossis, L. S., Gastaldelli, A., Horowitz, J. F., Endert, E., \& Wolfe, R. R. (1993). Regulation of endogenous fat and carbohydrate metabolism in relation to exercise intensity and duration. American Journal of Physiology - Endocrinology and Metabolism, 265(3 28-3), 380-391. https://doi.org/10.1152/ajpendo.1993.265.3.e380

Rubinsztein, D. C., Codogno, P., \& Levine, B. (2012). Autophagy modulation as a potential therapeutic target for diverse diseases. Nature Reviews Drug Discovery, 11(9), 709-730. https://doi.org/10.1038/nrd3802

Russell, R. C., Yuan, H. X., \& Guan, K. L. (2014). Autophagy regulation by nutrient signaling. Cell Research, 24(1), 42-57. https://doi.org/10.1038/cr.2013.166

Sahu, R., Kaushik, S., Clement, C. C., Cannizzo, E. S., Scharf, B., Follenzi, A., Potolicchio, I., Nieves, E., Cuervo, A. M., \& Santambrogio, L. (2011). Microautophagy of Cytosolic Proteins by Late Endosomes. Developmental Cell, 20(1), 131-139. https://doi.org/10.1016/j.devcel.2010.12.003

Sikorska-Siudek, K., Olẹdzka-Orẹziak, M., \& Parzuchowska, B. (2006). Choroba wieńcowa wśród kobiet - Czy istnieje problem płci? Family Medicine and Primary Care Review, 8(3), 1110-1115.

Sureshbabu, A., Ryter, S. W., \& Choi, M. E. (2015). Oxidative stress and autophagy: Crucial modulators of kidney injury. Redox Biology, 4, 208-214. https://doi.org/10.1016/j.redox.2015.01.001

Sylow, L., Kleinert, M., Richter, E. A., \& Jensen, T. E. (2017). Exercise-stimulated glucose uptake-regulation and implications for glycaemic control. Nature Reviews Endocrinology, 13(3), 133-148. https://doi.org/10.1038/nrendo.2016.162

Takamura, A., Komatsu, M., Hara, T., Sakamoto, A., Kishi, C., Waguri, S., Eishi, Y., Hino, O., Tanaka, K., \& Mizushima, N. (2011). Autophagy-deficient mice develop multiple liver tumors. Genes and Development, 25(8), 795-800. https://doi.org/10.1101/gad.2016211

Tsentsevitsky, A. N., Kovyazina, I. V., \& Bukharaeva, E. A. (2019). Diverse Effects of Noradrenaline and Adrenaline on the Quantal Secretion of Acetylcholine at the Mouse Neuromuscular Junction. Neuroscience, 423, 162-171. https://doi.org/10.1016/j.neuroscience.2019.10.049

Tumbarello, D. A., Waxse, B. J., Arden, S. D., Bright, N. A., Kendrick-Jones, J., \& Buss, F. (2012). Autophagy receptors link myosin VI to autophagosomes to mediate Tom1-dependent autophagosome maturation and fusion with the lysosome. Nature Cell Biology, 14(10), 1024-1035. https://doi.org/10.1038/ncb2589

Uttenweiler, A., Schwarz, H., \& Mayer, A. (2005). Microautophagic vacuole invagination requires calmodulin in a Ca 2+-independent function. Journal of Biological Chemistry, 280(39), 33289-33297. https://doi.org/10.1074/jbc.M506086200

Van Loon, L. J. C., Greenhaff, P. L., Constantin-Teodosiu, D., Saris, W. H. M., \& Wagenmakers, A. J. M. (2001). The effects of increasing exercise intensity on muscle fuel utilisation in humans. Journal of Physiology, 536(1), 295-304. https://doi.org/10.1111/j.1469-7793.2001.00295.x

Vanzo, R., Bartkova, J., Merchut-Maya, J. M., Hall, A., Bouchal, J., Dyrskjøt, L., Frankel, L. B., Gorgoulis, V., Maya-Mendoza, A., Jäättelä, M., \& Bartek, J. (2019). Autophagy role(s) in response to oncogenes and DNA replication stress. Cell Death and Differentiation. https://doi.org/10.1038/s41418-019-0403-9

Wasserman, D. H., Spalding, J. A., Lacy, D. B., Colburn, C. A., Goldstein, R. E., \& Cherrington, A. D. (1989). Glucagon is a primary controller of hepatic 
Research, Society and Development, v. 10, n. 16, e441101624223, 2021

(CC BY 4.0) | ISSN 2525-3409 | DOI: http://dx.doi.org/10.33448/rsd-v10i16.24223

glycogenolysis and gluconeogenesis during muscular work. American Journal of Physiology - Endocrinology and Metabolism, 257(1). https://doi.org/10.1152/ajpendo.1989.257.1.e108

Wasserman, David H. (2009). Four grams of glucose. American Journal of Physiology - Endocrinology and Metabolism, 296(1), 11-21. https://doi.org/10.1152/ajpendo.90563.2008

Wirth, M., Joachim, J., \& Tooze, S. A. (2013). Autophagosome formation-The role of ULK1 and Beclin1-PI3KC3 complexes in setting the stage. Seminars in Cancer Biology, 23(5), 301-309. https://doi.org/10.1016/j.semcancer.2013.05.007

Wu, C. A., Huang, D. Y., \& Lin, W. W. (2014). Beclin-1-independent autophagy positively regulates internal ribosomal entry site-dependent translation of hypoxia-inducible factor $1 \alpha$ under nutrient deprivation. Oncotarget, 5(17), 7525-7539. https://doi.org/10.18632/oncotarget.2265

Yue, Z., Jin, S., Yang, C., Levine, A. J., \& Heintz, N. (2003). Beclin 1, an autophagy gene essential for early embryonic dev elopment, is a haploinsufficient tumor suppressor. Proceedings of the National Academy of Sciences of the United States of America, 100(25), 15077-15082. https://doi.org/10.1073/pnas.2436255100

Zhang, Jiangwei, Kim, J., Alexander, A., Cai, S., Tripathi, D. N., Dere, R., Tee, A. R., Tait-Mulder, J., Di Nardo, A., Han, J. M., Kwiatkowski, E., Dunlop, E. A., Dodd, K. M., Folkerth, R. D., Faust, P. L., Kastan, M. B., Sahin, M., \& Walker, C. L. (2013). A tuberous sclerosis complex signalling node at the peroxisome regulates mTORC1 and autophagy in response to ROS. Nature Cell Biology, 15(10), 1186-1196. https://doi.org/10.1038/ncb2822

Zhang, Jianhua. (2015). Teaching the basics of autophagy and mitophagy to redox biologists-Mechanisms and experimental approaches. Redox Biology, 4, 242259. https://doi.org/10.1016/j.redox.2015.01.003

Zhang, X. D., Qi, L., Wu, J. C., \& Qin, Z. H. (2013). DRAM1 Regulates Autophagy Flux through Lysosomes. PLoS ONE, 8(5). https://doi.org/10.1371/journal.pone.0063245

Zhou, F., Wu, Z., Zhao, M., Murtazina, R., Cai, J., Zhang, A., Li, R., Sun, D., Li, W., Zhao, L., Li, Q., Zhu, J., Cong, X., Zhou, Y., Xie, Z., Gyurkovska, V., Li, L., Huang, X., Xue, Y., ... Segev, N. (2019). Rab5-dependent autophagosome closure by ESCRT. Journal of Cell Biology, 218(6), 1908-1927. https://doi.org/10.1083/JCB.201811173 